\title{
Digital Storytelling and the Role of Meta-Orators in Institutional Listening
}

Naomi Sunderland and Nicole Matthews

Listening to personal stories in health-related institutions is widely recognized as a challenging and potentially discomforting activity that often requires courage and resilience on the part of the listener. Through a series of international case studies of the ways stories are being listened to in health and social policy settings internationally, and engagement with current listening literature, we identified four key "meta-oratory" roles at work in promoting and supporting listening in institutional health contexts: curator, host, caretaker, and broker. We refer to these roles as meta-oratory due to the often profound effects they can have on how stories are listened to, received, and applied (or not) in health settings. In this article we offer a complex view of listening in institutions and query the ways that existing meta-oratory role holders can support active, applied, and potentially transformative listening for health.

$\bigcap$ ver the past thirty years, personal storytelling has become a staple in social media and a key element in the workings of public institutions, government, nongovernment, and professional organizations. With institutionalization, though, comes new dimensions to the unavoidable mediation of personal narratives: the filtering and reshaping of meanings to accord with institutional and

Storytelling, Self, Society, Vol. 15, №. 1 (2019), pp. 31-42. Copyright @ 2019 by Wayne State University Press, Detroit, MI 48201 
organizational needs, strategies, and ways of seeing. Much of what has been written about the practice of digital storytelling in particular focuses on the collection of stories (for example, Meadows; Koh) or the value to the storyteller of participating in the storytelling process (for example, Burgess; Hull and Katz; Rossiter and Garcia). However, a few organizations-like the US Storycenter's Silence Speaks ${ }^{1}$ and the UK's Patient Voices ${ }^{2}$ - have built up a wealth of experience of not just gathering stories but of using them to prompt professional learning and improvement in clinical service provision and community health. The work of these organizations underscores the importance not only of people telling stories about their experiences of health and care, but also of health professionals and policy makers actively listening and responding to these experiences. It is this listening - and the complexities and potential of achieving it - that is at the center of this article.

In the past eight years we have worked collaboratively as researchers, storytelling and listening facilitators, authors, and teachers to explore the diverse and myriad ways that digital stories are being listened to in health and social policy contexts internationally. We use the term "digital storytelling" here to refer to life-story telling in a variety of mediated forms deployed to prompt social change. This article draws on our own experiences as storytelling and listening facilitators alongside a series of international case studies exploring the ways in which digital stories are listened to in health and social policy (see Matthews and Sunderland). We begin by outlining the complex nature of listening and some implications of that complexity for institutional listening. We extend this discussion by outlining four "meta-oratory" roles in storytelling and listening that emerged from our international case studies and the existing literature on listening. Such roles-which include curators, hosts, caretakers, and brokers (Dreher) of stories and listening - can be taken on deliberately or unconsciously by those involved in institutional listening work. We offer this article in hope that potentially new ways of seeing and thinking about listening and meta-oration will enable new or more conscious ways of being and doing in the vital areas of institutional listening, curating, hosting, and brokering for health. 


\section{The Complexity of Listening}

Extending on the work of Couldry and others (for example, Iedema, "Bureaucratic," "Multimodality"; Silverstone; Sunderland), we frame the process of listening to digital stories as involving a series of processes of "mediation." We adopt Silverstone's definition of mediation as the "movement of meanings" to support our understanding of listening and mediation:

Mediation involves the movement of meaning from one text to another, from one discourse to another, from one event to another. It involves the constant transformation of meanings, both large scale and small, significant and insignificant, as media texts and texts about media circulate in writing, in speech and audiovisual forms, and as we, individually and collectively, directly and indirectly, contribute to their production. (Silverstone, 13)

By emphasizing the way stories are subject to intended and unintended processes of mediation we acknowledge the inevitable dislocations and transformations of meaning and agency that occur through listening. A core assumption here is that processes of listening and mediation are never neutral or "controllable." Rather, they are always socially embedded, interpretive, and politically, economically, and ethically significant (Silverstone). Mediation and listening are inevitably located within sociohistorical and political trajectories and systems and intimately imbricated with storytelling itself. Any process of mediation necessarily involves complex repeated processes of translation and resemiotization (movement of meaning into new languages or semiotic systems), remediation (movement of meaning into new media types such as websites, reports, films, and meetings), and recontextualization (movement of meanings into new social contexts such as education, policy making, or service delivery). Hence, there are many and repeated instances of listening and mediation at play in institutions that can occur way past the initial point of deliberate and known contact between storytellers and listeners. For example, as we describe in our book, Digital Storytelling in Health and Social Policy: Listening to Marginalised Voices, images and stories, emerging from a place-based health project reappeared years after their planned and carefully curated exhibition in a gallery on the walls of a hospital and a university research center, and part of university marketing materials (Matthews and Sunderland). Thus, even where projects are carefully planned with fastidious ethics agreements 
with storytellers, the digitalized stories emerging from these projects can-and perhaps should-have unanticipated afterlives.

Understanding listening as a process of mediation requires us to pay particular attention to the ways that existing power relations are produced, reproduced, and potentially transformed in planned and unplanned institutional listening engagements. Here, we draw attention to recent scholarship on the politics of listening (see, for example, Dreher; Lacey; Lloyd; Thill, "Courageous," "Listening”). For these scholars, listening is not simply an interpersonal or individual process but one in which collective identities and inequalities of power are implicated and potentially transformed or reproduced. Bickford's account of listening, for example, stresses the dissonances, conflict, disagreements, and disjunctions that are part of political listening. Political listening that potentially disrupts existing power relations and related practices in health and other settings is often difficult, emotionally draining cultural work that requires openness to others, a commitment to ongoing engagement, and, frequently, courage (Bickford; Thill, "Courageous," "Listening"; Lloyd; Matthews). A key question that has emerged from our work, then, is how are we preparing and supporting listeners to listen in courageous and potentially challenging ways?

\section{Using "Meta-Orators" to Promote and Support Listening}

We have become increasingly aware of the importance of institutional "meta-orators" (Matthews and Sunderland 26-31) in shaping the ways that stories are listened to and responded to in institutional settings. While digital storytelling is often imagined in terms of relatively "free" and uncensored stories of lived experience, recognizing and acknowledging the role of meta-orators places the emphasis on their opportunities and responsibility to shape the listening environment. We use the term "meta-orator" to recognize that the meaning of stories is shaped and added to by the contexts and agents of listening in institutions. The way stories are introduced, combined, housed, categorized and labeled, explained, and presented within an institutional setting, for example, can substantially affect their meanings and significance. We argue that meta-orators also have a powerful but under-recognized role in preparing and supporting institutional listeners to listen to people's stories in open, nondefensive, applied, and antioppressive ways. 
Making the distinction between the first two meta-oratory roles of curator and host allows us to differentiate between listening environments that are created to facilitate listening to particular selections of stories-such as galleries or museums that display a specific "collection" of stories-and more "anonymous" and generalized hosting platforms (such as Facebook). Curated collections are often themed or gathered together with a particular purpose in mind. An example of a curated collection of stories is the $U N_{4} U$ digital photography contests held by the United Nations Development program in 2014. ${ }^{3}$ The $U N 4 U$ competition organizers called for submissions of original photos via Instagram or email on the theme of gender inequality. Another example of curation is Brenda Brueggeman's role in pulling together and introducing digital stories from the US Digital Archive of Literacy Narrative (DALN) ${ }^{4}$ around deaf identity and literacy into an "exhibition" of stories within the collection (Comer and Harker).

In contrast to curators, hosts might provide an environment for listening and engagement without any particular knowledge of or control over story content. Hosts that do not employ a curatorial role are typically more concerned with creating spaces and environments and providing an environment for "guests" to share or listen to stories. An example of a hosted but not necessarily curated listening environment might include YouTube, Vimeo, Instagram, or Google sites. Although the host may not curate a collection of stories, the hosting environment will fundamentally influence the listening environment, as well as shaping which kinds of content can be shared, which are highlighted, and how content is tagged, categorized, and searched.

Our case studies and facilitating work have also indicated a third meta-oratory role in story listening: that of the caretaker. This role can be distinct frombut also overlapping with-both the curating and hosting roles. Caretaking involves monitoring the ethical use and reuse of mediated stories that have been moved from the original storyteller. Our conversations with storytelling and listening facilitators suggest that in building in ethical practices of seeking consent, generating stories, and negotiating the conditions under which those stories might be listened to, storytelling facilitators often take on roles as story caretakers, at least in the early phases of a storytelling project (for example, Gubrium, Hill, and Flicker). Where story collection has been built into the roles and routines of large institutions, for example in the Welsh National Health Service (Tee and Gray), those caretaking roles may be ongoing, if under-recognized and under-resourced. 
In the case of commercially hosted environments for storytelling and listening such as personal websites, social media profiles, and blogs, there is often an interesting mixture of the roles of host, curator, and caretaker. The storyteller/host of personal sites also plays a meta-oratory role as curator of his or her own collection of story artifacts. Depending on their intentions, storytellers can play a more or less pronounced "curating" role in the presentation of their autobiographical materials. A user who hosts a website to promote awareness of acquired brain injury and support fellow brain injury survivors, for example, may be more interested in actively hosting a site for others - that is, for listeners - than deliberately curating a particular collection of stories.

The fourth meta-oratory role we recognize draws from Tanja Dreher's work on listening brokers. Dreher sees a broker as an agent with some institutional power, for instance, members of funding bodies or policy makers within government departments that may have commissioned a particular set of digital stories, who can create links to new hosts-such as broadcasters-and their viewers and listeners. Higher education teachers and professional educators using collections of stories in classrooms could be seen as acting as brokers (Comer and Harker). Equally, researchers, especially action researchers, could be considered brokers. For example, Locock and her colleagues in their work using narratives from Healthtalkonline ${ }^{5}$ as part of an experience-based co-design project in which staff and patients worked together on redesigning systems and processes, using discussions catalyzed by listening to digital stories.

\section{Implications for Storytelling and Listening Practice and Efficacy}

All four of the meta-oratory roles outlined here can influence the ways stories-digital or otherwise-are listened to, interpreted, ignored, or acted on. People and organizations who play roles as meta-orators contribute a layer of contextual meaning to any presentation of digital stories. Consequently, while often neglected, these roles are practically, politically, and ethically important. Nancy Thumin, for example, draws attention to the ways that institutional collections of stories such as the Museum of London's Voice of London ${ }^{6}$ and BBC Wales' Capture Wales 7 mediate and "curate" participant stories in several important ways. She notes in particular the somewhat illusionary nature of the stories representing "everyday" and "ordinary" people's voices in what is often a 
relatively highly produced outcome of several waves of personal, interpersonal, and institutional mediation. Here the "ordinary" individual's voice becomes intermingled, for good or ill, with institutional voices that call on various professional, disciplinary, and personal discourses of decision makers and technicians alike. Tony Sumner from Patient Voices underlines the value of carefully aligning a patient story used in a formal meeting such as the board of a Health Trust with the agenda of that meeting, a practice instituted in Manchester Mental Health Trust (Matthews and Sunderland, 97). In this instance, the meta-oratory function of the institution underlines the significance of "ordinary" voices, providing a "steer from the top" that listening to such voices is important. On the flip side, the presence of such patient voices may allow institutions to present themselves as responsive in a way that has been described as "[playing the] user card" (Harrison and Mort).

If digital storytelling projects aim toward democratization and social justice, all of these meta-oratory roles are implicated in the success or otherwise of such aspirations. A caretaking role can honor agreements with original storytellers regarding reuse and controlling the remediation and recontextualization of stories. While such caretaking may be guided by a strong sense of ethics, tethering mediated stories to the original storyteller can actually inhibit their use for policy making or social justice purposes, limit their reach and impact outside of the storytellers' and project partners' immediate political, cultural, and social spheres of influence, experience, or imagination.

As we have explored in more detail elsewhere (Matthews and Sunderland, 33-34) the conflation of individual storytellers' voice with institutional voices is most apparent in listening environments that are hosted or curated by professional media and public relations. Here the curatorial role can take on a particular focus and intention in making the institution look good-that is, socially responsible, ethical, engaged - to outside audiences via its selection and display of citizen-authored digital stories. Even as it uses the language of ethical engagement, this curatorial intentionality and selectivity can depart significantly from other types of curatorship that are focused on social justice, health, or well-being content and themes.

The threats of such institutional recurating are acknowledged by Amy Hill from Silence Speaks. She notes "We definitely have seen with some of our partners in the global public health context that there's a really big disconnect between programmatic people that we might have worked with on a project, and marketing 
and communication people who view the stories as tools for marketing and communications" (personal communication, 2016). Moving beyond the role of facilitator into the role of caretaker, Hill shared with us strategies for attempting to preempt inappropriate public-relations-oriented uses of sensitive stories. She describes, for instance, an orientation activity developed for all members of a partner organization, including those in marketing and communications positions, stressing how to contextualize and present stories, followed by a form asking all staff to agree to particular ethical protocols in their use of stories. As Hill commented on the limits of her ability to act as caretaker for stories developed in international settings: "I can't actually police and say they're actually doing that, but those are the kinds of things that I like to do for my own peace of mind" (personal communication, 2016).

Finally, across many contexts of our work, we have noted a tendency for institutional meta-orators and others to favor certain kinds of stories that are deemed to be more "listenable." When we talked with Australian former state government policy advisor, executive, academic, writer, and long-time disability activist Dr. Donna McDonald about her use of stories in policy making, for example, we asked her what kinds of stories worked best in policy making in her experience. Donna replied: "The stories that work best are the stories that have a happy ending." "Listenable" stories are often seen as those that aren't too "ranty" or negative with hospital administration boards and staff. While this selectivity around choosing positive and "listenable" stories is quite widespread, it raises significant concerns about reproducing oppression and dominance through forum control. Such control and restriction is quite at odds with the underlying social justice values and imperatives of digital and other forms of storytelling for health. Can we find ways to prepare and support listeners to antioppressively and nondefensively hear the unhappy and ranty stories as well?

\section{Conclusion}

Storytellers and their allies in many ways set out to do extraordinary things-to amplify stifled voices, to reshape hierarchies of expertise, and to tap into vital new insights on the world. While we share these aspirations, our own experiences and research suggest that a complex and challenging story of change is at play. In highlighting the importance of the meta-oratory roles of curator, host, caretaker, 
and broker, we hope to draw attention and energy to some new and conscious ways of enhancing and sustaining listening in institutions for health.

Associate Professor Naomi Sunderland lectures in the School of Human Services and Social Work and is Co-Convenor of the Music and Communities Research Area at the Queensland Conservatorium Research Centre, Griffith University. Naomi is a descendant of the Wiradjuri First People of Australia. She has an extensive background in participatory, creative, and community-based research in the areas of health, well-being, and arts-based community development. She has collaborated on many arts and health research projects, including: trauma informed song writing with refugees and asylum seekers in Australia and Finland; the 1,ooo Voices Disability Life Stories Project; a social determinants of health evaluation of the Scattered People asylum seekers and refugee music group; and a participatory intercultural evaluation of multiarts work with Barkly Regional Arts in the Northern Territory. Naomi teaches in the First Australians and Social Justice team at Griffith University and specializes in topics concerning transformative intercultural and immersive education, equity, and diversity. Naomi has a $\mathrm{PhD}$ in applied ethics and human rights from the Queensland University of Technology. She has worked in government and nongovernment organizations and universities in Canada and Australia. She has published widely on the topics of health promotion partnerships, music and well-being, storytelling, listening, disability and happiness, and transformative ethics. Naomi is also an active singer, songwriter, and performer and has released several albums internationally.

Nicole Matthews is a senior lecturer in media and cultural studies at Macquarie University in Sydney, Australia. Her most recent book, written with Naomi Sunderland, is Digital Storytelling in Health and Social Policy: Listening to Marginalised Voices (Routledge, 2017). She has been involved in a number of collaborative research projects in Australia and the United Kingdom exploring the way people use visual and digital media to tell stories drawing on their own life experience. This work has included research on the way young Australian sign-language users employ video for storytelling, and analysis of a UK Lottery-funded project that brought together stories for the very young, written by disabled people and families of disabled children, with illustrations and animations by art, multimedia, and design students. Her current project focuses on the convergence between hearing aids and mobile phones and ways this newly mainstream technology might shape the understandings, identities, and practices of users. She continues to be interested in the way health professionals listen to service users and is also working on 
research with audiologists exploring barriers to listening to clients' lived experience in clinical settings.

\section{NOTES}

1. www.storycenter.org/silence-speaks.

2. www.patientvoices.org.uk/.

3. www.un.org/youthenvoy/2014/10/un4u-photo-contest-2014-gender-equality/.

4. www.thedaln.org/\#/home.

5. www.healthtalk.org/.

6. www.museumoflondon.org.uk/schools/session-detail?id=913.

7. www.bbc.co.uk/wales/audiovideo/sites/galleries/pages/capturewales.shtml.

\section{WORKS CITED}

Bickford, Susan. The Dissonance of Democracy: Listening, Conflict, and Citizenship. Cornell UP, 1996.

Burgess, Jean. E. "Hearing Ordinary Voices: Cultural Studies, Vernacular Creativity, and Digital Storytelling." Continuum: Journal of Media and Cultural Studies, vol. 20, no. 2, 2006, pp. 201-214.

Comer, Kathryn B., and Michael Harker. "The Pedagogy of the Digital Archive of Literacy Narratives: A Survey." Computers and Composition, vol. 35, 2015, pp. $65-85$.

Couldry, Nick. "Mediatization or Mediation? Alternative Understandings of the emergent Space of Digital Storytelling." New Media and Society, vol. 10, no. 3, 2008, pp. 373-391.

Donetto, Sara, et al. "Experience-Based Co-Design and Health Care Improvement: Realizing Participatory Design in the Public Sector." Design Journal, vol. 18, no. 2, 2015, pp. 227-248.

Dreher, Tanja. "A Partial Promise of Voice: Digital Storytelling and the Limits of Listening." Media International Australia, vol. 142, no. 1, 2012, pp. 157-166.

Gubrium, Aline C., Amy L. Hill, and Sarah Flicker. "A Situated Practice of Ethics for Participatory Visual and Digital Methods in Public Health Research and Practice: A Focus on Digital Storytelling." American Journal of Public Health, vol. 104, no. 9, 2014, pp. 1606-1614.

Harrison, Stephen, and Maggie Mort. "Which Champions? Which People? Public and 
User Involvement in Health Care as a Technology of Legitimation.” Social Policy and Administration, vol. 32 , no. 1, 1998, pp. 60-70.

Hull, Glynda, and Mira-Lisa Katz. "Crafting an Agentive Self: Case Studies of Digital Storytelling." Research in the Teaching of English, vol. 41, no. 1, 2006, pp. 43-81.

Iedema, Rick. "Bureaucratic Planning and Resemiotisation." Language in Performance, 2000, pp. 47-70.

. "Multimodality, Resemiotization: Extending the Analysis of Discourse as MultiSemiotic Practice.” Visual Communication, vol. 2, no. 1, 2003, pp. 29-57.

Koh, Angelica. “Digital Storytelling in Multicultural Singapore.” Digital Storytelling: Form and Content. Edited by Mark Dunford and Tricia Jenkins, Palgrave, 2017, pp. 49-56.

Lacey, Kate. Listening Publics: The Politics and Experience of Listening in the Media Age. John Wiley and Sons, 2013.

Lloyd, Justine. “The Listening Cure.” Continuum, vol. 23, no. 4, 2009, pp. 477-487.

Locock, Louise Glenn Robert, Annette Boaz, Sonia Vougioukalou, Caroline Shuldham, Jonathan Fielden, Sue Ziebland, Melanie Gager, Ruth Tollyfield, and John Pearcey. "Using a National Archive of Patient Experience Narratives to Promote Local Patient-Centered Quality Improvement: An Ethnographic Process Evaluation of 'Accelerated' Experience-Based Co-Design.” Journal of Health Services Research and Policy, vol. 19, no. 4, 2014, pp. 200-207.

Matthews, Nicole. "Learning to Listen: Epistemic Injustice and Gothic Film in Dementia Care Education.” Feminist Media Studies, vol. 16, no. 6, 2016, pp. $1078-1092$.

Matthews, Nicole, and Naomi Sunderland. Digital Storytelling in Health and Social Policy: Listening to Marginalised Voices. Routledge, 2017.

Meadows, Daniel. “Digital Storytelling: Research-Based Practice in New Media.” Visual Communication, vol. 2, no. 2, 2003, 189-193.

Rossiter, Marsha, and Penny Garcia. "Digital Storytelling: A New Player on the Narrative Field. New Directions for Adult and Continuing Education, vol. 126, 2010, pp. $37-48$.

Silverstone, Roger. Why Study the Media? Sage, 1999.

Sunderland, Naomi. "Virtuous or Vicious?: Agency and Representation in Biotechnology's Virtuous Cycle." Journal of Technical Writing and Communication, vol. 39, no. 4, 2009, pp. 381-400.

Tee, Anna, and Jonathan Gray. Learning to Use Patient Stories: Tools for Improvement 6. GIG CYMRU \& NHS Wales, 2012. www.10oolivesplus.wales.nhs.uk/stories. 
Thill, Cate. "Courageous Listening, Responsibility for the Other, and the Northern Territory Intervention." Continuum, vol. 23, no. 4, 2009, pp. 537-548.

_ . "Listening for Policy Change: How the Voices of Disabled People Shaped Australia's National Disability Insurance Scheme." Disability and Society, vol. 30, no. 1, 2015, pp. 15-28.

Thumim, Nancy. “'Everyone Has a Story to Tell': Mediation and Self-Representation in Two UK Institutions." International Journal of Cultural Studies, vol. 12, no. 6, 2009, pp. 617-638. 